\title{
A EDUCAÇÁo SUPERIOR EM Santa Catarina: um SÉCUlo DE HISTÓRIA (1917-2017)
}

\section{The higher education in Santa Catarina: one hundred OF HISTORY (1917-2017)}

\author{
Sherlon Cristina de Bastiani \\ Mestra em Educação pela Universidade Federal da Fronteira Sul. Professora da \\ Rede Municipal de ensino de Joaçaba. Santa Catarina - SC - Brasil \\ sherlondebastiani@gmail.com
}

Joviles Vitório Trevisol

Doutor em Sociologia pela Universidade de São Paulo. Pró-Reitor de Pesquisa e PósGraduaçáo da Universidade Federal da Fronteira Sul. Santa Catarina - SC - Brasil joviles.trevisol@uffs.edu.br

\section{Ludimar Pegoraro}

Doutor em Educação pela Universidade Federal do Rio Grande do Sul. Docente no Programa de Mestrado Profissional em Educação Básica e Mestrado Acadêmico em Desenvolvimento e Sociedade. Coordenador do grupo de Pesquisa em Políticas Públicas e Processos Formativos em Educação na Universidade Alto Vale do Rio do Peixe. Santa Catarina - SC - Brasil pegoraro1963@hotmail.com

\begin{abstract}
Resumo: Este trabalho apresenta os resultados de pesquisa sobre o processo de expansão/ interiorização da educação superior em Santa Catarina. É um estudo que visa analisar a evolução da educação superior catarinense a partir de especificidades (contextos e realidades) locais e regionais. A escolha está associada ao fato de o estado ter completado, em 2017, cem anos de implantação dos primeiros cursos superiores. A investigação foi desenvolvida por métodos e técnicas quantitativos e qualitativos. A pesquisa bibliográfica, se deu, sobretudo, com base em Cunha (2007), Saviani (2007, 2010), Romanelli (1989), Freitag (1980), Muniz (2006), Sampaio (2000), Pegoraro (2006, 2013), e Gumbowsky (2004). Já, a busca por dados quantitativos se deu, sobretudo, nas bases do Instituto Nacional de Estudos e Pesquisas Educacionais Anísio Teixeira (INEP). A pesquisa revela que a expansão em SC se deu por meio das fundaçóes educacionais de direito privado. $\mathrm{O}$ modelo fundacional foi hegemônico até os anos 2000, momento em que passa a ocorrer a expansão de IES públicas e de privadas com fins lucrativos. Do total de 94 instituiçóes em 2015, 88\% eram privadas com e sem fins lucrativos. A graduação a distância tem se expandido com altas taxas de crescimento, contudo, as matrículas em cursos presenciais de graduação ainda representam, em 2015, 72\% do universo de estudantes catarinenses.
\end{abstract}

Palavras-Chave: Educação Superior. Políticas de Expansão e Interiorização. Santa Catarina.

AвSTRACT: This paper presents the results of research on the process of creation and expansion / internalization of higher education in Santa Catarina. It is a study that aims to analyze the 
evolution of higher education in Santa Catarina based on local and regional specificities (contexts and realities). The choice is associated with the fact that in 2017 the State completed one hundred years of implementation of the first higher education courses. The research was developed through quantitative and qualitative methods and techniques. The bibliographical research was based on Cunha (2007), Saviani (2007, 2010), Romanelli (1989), Freitag (1980), Muniz (2006), Sampaio (2000), Pegoraro 2013), and Gumbowsky (2004). Already, the quest for quantitative data occurred mainly in the bases of the National Institute of Studies and Educational Research Anísio Teixeira (INEP). The research reveals that SC expansion has taken place through educational foundations under private law. The foundational model was hegemonic until the 2000s, when the expansion of public higher education courses and private higher education courses for-profit began to take place. Of the total higher education courses in 2015 (94 in all), 88\% were private (for-profit and non-profit). Graduation at distance has expanded with high growth rates; however, enrollments in undergraduate courses still represent, in 2015, 72\% of the universe of students from Santa Catarina.

KeYwords: Higher Education. Policies of Expansion and Internalization. Santa Catarina.

\section{Introduçáo}

Em 2017, a educação superior catarinense completou o seu primeiro centenário, respondendo hoje pela sétima colocação no país quanto ao número de cursos presenciais de graduação ofertados. De acordo com os dados do INEP, o estado de Santa Catarina possuía, em 2015, 328.683 tes em IES privadas e 79.724 em instituições públicas federais. (MEC/ INEP, 2017)

A expansão da educação superior em SC, a despeito de ter se dado sob a influência das políticas e das dinâmicas nacionais, ocorreu em tempos, formas e escalas muito particulares. Há especificidades que cabe reconhecer e analisar a partir dos contextos e realidades locais/regionais. As variáveis tempo e espaço e as dimensóes políticas, econômicas, sociais e culturais devem ser consideradas, pois exercem notável influência. A expansão está longe de ser homogênea, especialmente quando a análise recai sobre as especificidades regionais. A interiorizaçáo da educação superior em SC começou a ser impulsionada a partir da segunda metade dos anos 60, por meio de políticas públicas voltadas à criação das fundações educacionais de direito privado. Estas, majoritariamente criadas pelos poderes públicos municipais, foram responsáveis pela implantação dos primeiros cursos de graduação nas principais cidades de SC, dando origem, mais tar- 
de, às universidades comunitárias. A partir do início dos anos 2000, ocorre

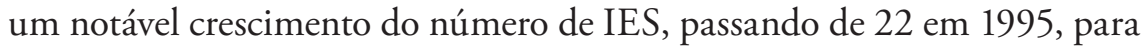
94 em 2015, sendo que 88\% delas são privadas. Além disso, 73\% das IES definem-se como faculdades; $14 \%$ como universidades; $11 \%$ como centros universitários e 2\% como institutos federais (MEC/INEP, 2015)

Tendo como propósito central a análise das principais dinâmicas que caracterizam a educação superior catarinense nos seus cem anos de história, este artigo apresenta os resultados de uma pesquisa realizada entre agosto de 2015 a julho de 2017, desenvolvida por métodos e técnicas tanto quantitativos quanto qualitativos. Além de uma revisão bibliográfica sobre a temática, tendo como referência Cunha (2007), Saviani (2007, 2010), Romanelli (1989), Freitag (1980), Muniz (2006), Sampaio (2000), Pegoraro (2006, 2013), Gumbowsky (2004), procedeu-se a uma extensa pesquisa documental, tendo como base leis, decretos, documentos, relatórios, sítios institucionais, boletins de balanço, livros, artigos, dissertaçôes e teses, bem como uma sistematização dos indicadores sobre número de IES, unidades/campi/polos, cursos, vagas, matrículas e concluintes, utilizando a base de dados de INEP, IBGE, Plataforma Sucupira e GeoCapes.

\section{A gênese da educaçáo superior catarinense: as primeiras faculdades}

Em Santa Catarina, assim como na maioria dos estados da federação, a implantação dos primeiros cursos superiores se deu apenas no século XX. A primeira IES criada foi o Instituto Politécnico, em 1917, sediado em Florianópolis, que surgiu da iniciativa de alguns profissionais residentes na capital catarinense como cirurgióes-dentistas, farmacêuticos, médicos, engenheiros, bacharéis em direito, um oficial da marinha e um guardalivros. Nela funcionavam os cursos de Odontologia, Farmácia, Engenharia e Comércio. Anos mais tarde, professores do próprio Instituto deram origem à Faculdade de Direito, que funcionou por meio de doaçóes até 1934 (PEGORARO, 2006).

No ano seguinte, em 1935, a Constituição Estadual estabeleceu que o governo do estado devia assumir a responsabilidade com a condução dessa instituição, determinando, em seu Art. 129, que competia ao "Estado 
custear o ensino normal e manter ou subvencionar o ginasial, o 'superior' e o profissional de artes e ofícios." (grifo nosso). No mesmo ano, por meio da Lei no 19, de 20 de novembro de 1935, a Faculdade de Direito foi estatizada. Três anos depois, o Decreto-Lei no 120, de 9 de junho de 1938, tornou-o instituto "livre e particular". Somente em 1956 a faculdade foi federalizada, ano em que o estado volta a ofertar o ensino superior público. O movimento da federalização assumia o viés de responsabilização do Estado sobre questôes públicas, embora o acesso à educação superior da época apenas estivesse à disposição de grupos sociais muito restritos.

\section{A criação da primeira Universidade Pública}

Do ponto de vista da ampliação das oportunidades de acesso à educação superior, a década de 1960 foi marcante para a sociedade catarinense. Até então, as faculdades isoladas predominavam, não só em Santa Catarina, mas em todos os estados, embora já existissem no cenário nacional destacadas instituições públicas e privadas como a UFPR, USP, UFRJ, UFRGS, UFMG, UFBA, as PUCs, dentre outras. Essas universidades nasceram a partir da aglutinação de cursos superiores isolados já existentes na época, especialmente as públicas, e se localizavam nas capitais.

Somente a partir da década de 1960 a política de expansão começa a ser delineada, momento em que Santa Catarina institui a sua primeira universidade pública e gratuita, a Universidade Federal de Santa Catarina (UFSC). Sancionada no dia 18 de dezembro de 1960, a Lei no 3.849/60 que deu origem à UFSC introduz no estado um modelo completamente novo de IES (a universidade), rompendo assim com a tradição de faculdades isoladas no estado. Sendo uma organização acadêmica universitária pública e gratuita, a instituição passa a ofertar, além do ensino, também pesquisa e extensão. Similarmente às demais universidades existentes, a UFSC foi criada a partir da aglutinação de diferentes faculdades e cursos isolados existentes em Florianópolis.

A criação da UFSC, ocorrida 43 anos após a implantação dos primeiros cursos superiores em Florianópolis, teve forte repercussáo, particularmente entre as lideranças políticas e educacionais das principais cidades de SC, que já vinham demandando ao governo estadual a interiorização 
da educação superior. Os municípios de maior porte econômico passam a pleitear a criação de instituições que viabilizassem a implantação e expansão da educação superior no Estado.

\section{A interiorizaçáo e a criaçáo da segunda Universidade Pública}

Os anos de 1960 e 1970 marcaram a primeira fase de expansão da educação superior em diversas regiōes catarinenses, seguindo uma política orientada pelo I Plano de Metas do Governo (I PLAMEG), ${ }^{1}$ que, ao determinar a reorganização da Secretaria da Educação e Cultura (Lei no 2.975, de 18/12/61), criou o Conselho Estadual de Educaçáo (CEE/SC), que teve decisiva importância no desenvolvimento da educação superior no interior nos anos seguintes. O CEE passa a incentivar e orientar a criaçáo de instituições na direção da interiorização e a administração pública estadual a adotar políticas específicas direcionadas à expansão.

Quando falamos da expansão, interiorização ou regionalização da educação superior em Santa Catarina, necessariamente precisamos nos referir ao sistema fundacional. As administraçóes públicas municipais e as lideranças empresariais e comunitárias das diferentes regióes passaram a requisitar a implantação de cursos superiores nas principais cidades do interior. A despeito das mobilizações que defendiam a criação de mais IES públicas (federais e estaduais), não havia naquele momento condiçóes políticas e orçamentárias para promover a expansão do ensino superior público e gratuito pelo interior do estado. Face à pressão proveniente das lideranças políticas, empresariais, religiosas, sociais e educacionais dos principais municípios, o governo estadual decide, por meio de inúmeras políticas e ações, apoiar a expansão por meio da criação de fundaçôes educacionais de direito privado. Foram elas que viabilizaram, naquele momento histórico, a criação de muitos cursos no interior e que, com o seu crescimento e fortalecimento, vieram a integrar um sistema de educação superior.

$\mathrm{Na}$ época, o acelerado processo de industrialização e de urbanização do país passou a demandar fortemente a expansão dos cursos de graduação e pós-graduação. No início da década, após treze anos de tramitação e debates, o Congresso Nacional aprovou as Diretrizes e Bases da Educação 
Nacional (LDB), sancionando a Lei no 4.024/61 em 20 de dezembro. A LDB regulamentou uma modalidade institucional que viria a ser amplamente apoiada e expandida em Santa Catarina: trata-se das fundaçóes educacionais de direito privado sem fins lucrativos. Em seu Art. 107, a Lei assim se refere:

Art. 107. O poder público estimulará a colaboração popular em favor das fundações e instituiçôes culturais e educativas de qualquer espécie, grau ou nível sem finalidades lucrativas, e facultará aos contribuintes do imposto de renda a redução dos auxílios ou doaçóes comprovadamente feitas a tais entidades. (Lei $\mathrm{n}^{\circ}$ 4.024/61)

Anos depois, em 1968, a Reforma Universitária também contribuiu para o fortalecimento do sistema fundacional ao estabelecer, em seu Art. $2^{\circ}$, que "o ensino superior indissociável da pesquisa será ministrado em universidades e, excepcionalmente, em estabelecimentos isolados, organizados como instituiçôes de direito público ou privado" (Lei no 5.540/68). A interiorização passou a ser concebida e implementada por meio das fundaçóes educacionais, também regulamentadas pelo Decreto-Lei no 200, de 1967. Em seu inciso IV, do Art. 5º o Decreto assim define fundação pública:

IV - Fundação Pública - a entidade dotada de personalidade jurídica de direito privado, sem fins lucrativos, criada em virtude de autorização legislativa, para o desenvolvimento de atividades que não exijam execução por órgãos ou entidades de direito público, com autonomia administrativa, patrimônio próprio gerido pelos respectivos órgãos de direção, e funcionamento custeado por recursos da União e de outras fontes. (Incluído pela Lei no 7.596 , de 1987)

Conforme descreve Pegoraro (2006), nos anos de 1960 começa a surgir, em municípios de médio e pequeno porte, um conjunto de instituiçóes privadas sem fins lucrativos. Trata-se de uma modalidade específica de fundaçóes educacionais, criadas pelo poder público municipal, porém 
de direito privado, definidas como IES filantrópicas e sem fins lucrativos (FRANTZ, 2004; PEGORARO, 2006; TREVISOL, 2015). Inserem-se no arco das entidades do "terceiro setor" na medida em que são públicas não-estatais, cuja finalidade principal é promover atividades de interesse público sem fins lucrativos. Na definição de Pegoraro (2006, p. 195) “[...] o Terceiro Setor é composto de organizaçóes privadas sem fins lucrativos, que atuam nas lacunas deixadas pelos setores públicos e privados, mas são atividades de interesse público, buscam o bem-estar social [...]".

As fundaçóes municipais passaram a ser o ente jurídico por meio do qual tornava-se possível solicitar ao Conselho Estadual de Educação a autorização dos primeiros cursos de graduação, cuja implantação se deu em estruturas alugadas e com limitadas condiçóes de infraestrutura de pessoal, bibliotecas e laboratórios. Por serem entidades públicas de direito privado, a cobrança de mensalidades tornou-se possível, constituindo-se, ao longo do tempo, como a principal fonte de financiamento das IES catarinenses. De forma lenta e progressiva, o Conselho Estadual de Educação passou a autorizar os primeiros cursos, voltados, na sua grande maioria, para o atendimento das necessidades do campo educacional e da administração pública e de empresas. Priorizou-se, na fase inicial, a implantação dos cursos de Administração, Contabilidade, Pedagogia, Letras, Ciências (Licenciatura Curta), Estudos Sociais e Direito.

Para demonstrar a pertinência desse período, apresentamos, no Quadro 1, a relação das instituiçóes criadas no período de 1964 a 1986.

Analisando o Quadro 1, é possível identificar, pelo número de fundaçôes criadas, que Santa Catarina assume uma política diferenciada dos demais estados ao criar um sistema de educação superior basicamente organizado a partir de fundaçóes. Num período de 22 anos, entre 1964 a 1986, foram criadas 21, sendo 8 delas na década de 1960, 12 nos anos de 1970 e uma apenas na década de 1980. Desse total, 20 foram ciadas num período de 14 anos; entretanto, de 1968 a 1976, num período de 8 anos, foram criadas 13 fundaçôes.

É importante destacar que todas as fundaçóes foram criadas pelo poder público, 20 delas pelos legislativos municipais e uma apenas pelo legislativo estadual, a Fundação Educacional de Santa Catarina (FESC), instituição que, na sequência, por iniciativa do governo do Estado, por meio do Decreto no 2.802, de 20 de maio de 1965, criou a segunda universidade 


\begin{tabular}{|c|c|c|c|c|}
\hline Instituição & Sigla & $\begin{array}{l}\text { Ano de } \\
\text { criação }\end{array}$ & Cidade & Região \\
\hline $\begin{array}{l}\text { Fundação Educacional da Região de } \\
\text { Blumenau }\end{array}$ & FURB & 1964 & Blumenau & Vale \\
\hline $\begin{array}{l}\text { Fundação Educacional do Sul de Santa } \\
\text { Catarina }\end{array}$ & FESSC & 1964 & Tubarão & Sul \\
\hline Fundação Joinvillense de Ensino & FURJ & 1965 & Joinville & Norte \\
\hline $\begin{array}{c}\text { Fundaçáo das Escolas Unidas do } \\
\text { Planalto Catarinense }\end{array}$ & UNIPLAC & 1965 & Lages & Serrana \\
\hline Fundação do Estado de Santa Catarina & FESC & 1965 & Florianópolis & $\begin{array}{l}\text { Grande } \\
\text { Florianópolis }\end{array}$ \\
\hline $\begin{array}{l}\text { Faculdade de Administração de } \\
\text { Empresas do Alto Vale do Itajaí }\end{array}$ & FEDAVI & 1966 & Rio do Sul & Vale \\
\hline Fundação Educacional de Criciúma & FUCRI & 1968 & Criciúma & Sul \\
\hline $\begin{array}{c}\text { Fundação Universitária do Oeste } \\
\text { Catarinense }\end{array}$ & FUOC & 1968 & Joaçaba & Oeste \\
\hline $\begin{array}{c}\text { Fundação Educacional do Planalto } \\
\text { Norte Catarinense }\end{array}$ & FUNPLOC & 1970 & Canoinhas & $\begin{array}{l}\text { Planalto } \\
\text { Norte }\end{array}$ \\
\hline $\begin{array}{l}\text { Fundação de Ensino do Polo } \\
\text { Geoeducacional do Vale do Itajaí }\end{array}$ & FEPEVI & 1970 & Itajaí & Vale \\
\hline $\begin{array}{c}\text { Fundaçáo de Ensino do } \\
\text { Desenvolvimento do Oeste }\end{array}$ & FUNDESTE & 1971 & Chapecó & Oeste \\
\hline $\begin{array}{c}\text { Fundaçáo Educacional e Empresarial } \\
\text { do Alto Vale do Rio do Peixe }\end{array}$ & FEMARP & 1971 & Videira & Oeste \\
\hline $\begin{array}{l}\text { Fundação Educacional do Alto Vale do } \\
\text { Rio do Peixe }\end{array}$ & FEARPE & 1971 & Caçador & Oeste \\
\hline $\begin{array}{c}\text { Fundação Educacional do Norte } \\
\text { Catarinense }\end{array}$ & FUNORTE & 1971 & Mafra & $\begin{array}{l}\text { Planalto } \\
\text { Norte }\end{array}$ \\
\hline Fundação Educacional de Brusque & FEBE & 1973 & Brusque & Vale \\
\hline Fundação Educacional Barriga Verde & FEBAVE & 1974 & Orleans & Sul \\
\hline $\begin{array}{c}\text { Fundação Educacional do Alto } \\
\text { Uruguai Catarinense }\end{array}$ & FEAUC & 1976 & Concórdia & Oeste \\
\hline $\begin{array}{c}\text { Fundação Educacional do Planalto } \\
\text { Catarinense }\end{array}$ & FEPLAC & 1976 & Curitibanos & Serrana \\
\hline $\begin{array}{c}\text { Fundação Educacional Regional } \\
\text { Jaguaraense }\end{array}$ & FERJ & 1976 & $\begin{array}{l}\text { Jaraguá do } \\
\text { Sul }\end{array}$ & Norte \\
\hline $\begin{array}{c}\text { Fundação Educacional do Extremo } \\
\text { Oeste de Santa Catarina }\end{array}$ & FENESC & 1978 & $\begin{array}{l}\text { São Miguel } \\
\text { do Oeste }\end{array}$ & Oeste \\
\hline $\begin{array}{l}\text { Fundação Educacional dos Municípios } \\
\text { do Alto Irani }\end{array}$ & FEMAI & 1986 & Xanxerê & Oeste \\
\hline
\end{tabular}

Quadro 1: Relação das Fundaçóes educacionais de ensino superior no estado de Santa Catarina criadas no período de 1964 a 1986

Fonte: Pegoraro (2006, p. 207-208); Trevisol (2015, p. 515). Elaboração dos autores. 
catarinense, a Universidade do Estado de Santa Catarina (UDESC). Essa universidade estadual surgiu da aglutinação da Faculdade de Educação (FAED), do Centro de Estudos e Pesquisas Educacionais (CEPE), da Fundação Educacional de Santa Catarina (FESC) e da Faculdade de Engenharia de Joinville, as demais fundaçóes continuaram atuando como faculdades isoladas.

Conforme destaca Mathias (2015, s/p), a UDESC constava do Plano de Metas (1961-1966) do então Governador Celso Ramos. Cabe destacar que em 1966 o então governador Ivo Silveira assumiu com o compromisso de implementar o Plano de Metas, que previa interiorizar a educação superior. Ao longo do seu mandato foi aprovado o Plano Estadual de Educação (PEE 1969-1980) que estabelecia o

Entrosamento entre a Universidade para o Desenvolvimento do Estado de Santa Catarina, UDESC, e a Universidade Federal de Santa Catarina, UFSC, para que estas, através da formação de grupo interuniversitário, liderem o desenvolvimento do ensino superior no Estado, vinculem ou assistam as diversas unidades isoladas do interior e fixem, através de plano específico a ser coordenado com o Conselho Estadual de Educação, a política de expansão desse ramo de ensino. (UDESC, 1969, p. I. 14)

Foi o que ocorreu em 1968 quando a UDESC foi designada para desenvolver um estudo de viabilidade técnica e financeira para a instalação dos primeiros cursos de nível superior no Oeste catarinense. Até então os cursos superiores ficavam localizados na Regiáo Serrana (em Lages) e na região litorânea. $\mathrm{O}$ estudo desenvolvido destacou a população de 285.961 habitantes, indicou ainda a existência de 12.076 alunos matriculados no $1^{\circ}$ ciclo dos diversos cursos de Ensino Médio e de 2.143 , no $2^{\circ}$ ciclo. Enfatizou que a região náo possuía cursos técnicos e que, além dos estabelecimentos de ensino comercial, havia apenas um ginásio agrícola no município de Concórdia. Apontou, em conclusão, que Joaçaba era a cidade adequada para a implantaçáo de curso superior (UDESC, 2009). Dessa forma, em 1972, iniciam-se as aulas do primeiro curso superior na regiáo Oeste, a única do estado que ainda não contava com cursos superiores. 
Retomando a análise dos dados do Quadro 1, é possível constatar que num período muito curto as fundações são instaladas nas diferentes regióes do estado. Praticamente todos os municípios de médio e grande porte passaram a ter instituições de educação superior. Os municípios, de um modo geral, empreenderam esforços nessa direção, pois a presença de cursos superiores era tida como vantagem competitiva e forma de atrair estudantes e professores mais qualificados. A expansão trouxe consigo a necessidade de criar uma entidade responsável pela coordenação das açóes e iniciativas das diferentes fundaçóes. Assim, em 1974 foi criada a Associação Catarinense das Fundaçôes Educacionais (ACAFE).

A partir da segunda metade da década de 1980, inicia-se em Santa Catarina um amplo movimento que visava transformar as fundações educacionais em universidades. Diversos fatores estáo na raiz desse processo, cabendo destaque para o fato de que as fundaçóes haviam crescido significativamente, tanto do ponto de vista acadêmico (número de cursos, professores e funcionários) quanto de infraestrutura. Além disso, começava a se fazer presente um forte apelo das comunidades regionais por mais oportunidades de formação aos jovens, principalmente os oriundos das famílias que não possuíam condições de manter seus filhos estudando em centros urbanos. A questáo de organizar uma IES no modelo de universidade também conferiria mais autonomia ao ente, por exemplo na proposição de novos cursos.

Para melhor acompanharmos desse processo, apresentamos o Quadro 2, que mostra a transformação das instituiçôes em universidades, acompanhadas dos respectivos anos de reconhecimento.

Considerando o Quadro 1 comparativamente ao Quadro 2, podemos observar redução no número de IES com a criação das universidades, visto que houve aglutinação de instituições (fundaçôes) que, para cumprir legalmente as condiçóes necessárias para o encaminhamento dos processos e obtenção de reconhecimento como universidade, deveriam apresentar um maior número de cursos e/ou áreas de conhecimento. ${ }^{2}$ Como isoladamente não era possível atender tais exigências, a saída foi criar uma nova instituição que congregasse as fundaçôes pretendentes ao reconhecimento.

Com exceção da UDESC, as demais universidades são reconhecidas a partir da segunda metade da década de 1980, período em que as políticas 


\begin{tabular}{|c|c|c|c|}
\hline Fundação & Instituição & $\begin{array}{l}\text { Ano de } \\
\text { reconhecimento }\end{array}$ & Cidade \\
\hline UDESC & Universidade do Estado de Santa Catarina & 1965 & Florianópolis \\
\hline FURB & Universidade Regional de Blumenau - FURB & 1986 & Blumenau \\
\hline FEPEVI & Universidade do Vale do Itajaí - UNIVALLI & 1989 & Itajaí \\
\hline FESSC & $\begin{array}{c}\text { Universidade do Sul de Santa Catarina - } \\
\text { UNISUL }\end{array}$ & 1989 & Tubarão \\
\hline $\begin{array}{c}\text { FUOC, } \\
\text { FEMARP, } \\
\text { FUNDESTE, } \\
\text { FENESC, } \\
\text { FEMAI }\end{array}$ & $\begin{array}{c}\text { Universidade do Oeste de Santa Catarina - } \\
\text { UNOESC }\end{array}$ & 1995 & Joaçaba \\
\hline FURJ & Universidade da Região de Joinville & 1996 & Joinville \\
\hline $\begin{array}{l}\text { FEARPE, } \\
\text { FUNPLOC, } \\
\text { FUNORTE, } \\
\text { FEAUC, } \\
\text { FEPLACI }\end{array}$ & Universidade do Contestado - UnC & 1997 & Caçador \\
\hline FUCRI & $\begin{array}{c}\text { Universidade do Extremo Sul Catarinense - } \\
\text { UNESC }\end{array}$ & 1997 & Criciúma \\
\hline UNIPLAC & $\begin{array}{l}\text { Universidade do Planalto Catarinense - } \\
\text { UNIPLAC }\end{array}$ & 1999 & Lages \\
\hline FERJ & $\begin{array}{l}\text { Centro Universitário de Jaraguá do Sul - } \\
\text { UNERJ }\end{array}$ & 2000 & $\begin{array}{l}\text { Jaraguá do } \\
\text { Sul }\end{array}$ \\
\hline FEDAVI & $\begin{array}{c}\text { Universidade da Região do Alto Vale do } \\
\text { Itajaí - UNIDAVI }\end{array}$ & 2001 & Rio do Sul \\
\hline FUNDESTE & $\begin{array}{l}\text { Universidade Comunitária Regional de } \\
\text { Chapecó - UNOCHAPECÓ }\end{array}$ & 2002 & Chapecó \\
\hline FEBE & Centro Universitário de Brusque - UNIFEBE & 2003 & Brusque \\
\hline FEARPE & Universidade Alto Vale do Rio do Peixe & 2009 & Caçador \\
\hline
\end{tabular}

\section{Quadro 2: Criaçáo das Universidades a partir das Fundaçóes Educacionais no estado de Santa Catarina}

Fonte: Pegoraro (2006, p. 120 e 123); Trevisol (2015, p. 515). Elaboração dos autores.

neoliberais começam a influenciar as decisóes dos governos federal e estaduais. De forma mais acentuada, deliberadamente favorece a aglutinação de instituiçóes privadas, especialmente do terceiro setor, fortalecendo o argumento de Fernandes (2002) de que elas não são instituiçôes particulares, mas públicas, porém administradas de forma privada. 
A UDESC é a única instituição pertencente ao sistema que oferece educação superior gratuita. Ela assumiu a característica de instituição de direto público somente em 1989, com a nova Constituição do Estado de Santa Catarina. Até então, era mantida como as demais, cobrando mensalidades. A partir da Constituição, atendendo ao que determina o Art. 169, que trata do ensino superior, e o Art. 39 das disposiçóes transitórias, e por pressóes dos estudantes que cobravam do Estado maior participação com investimentos na educação pública superior, a UDESC passou à forma de fundação pública mantida pelo Estado.

A partir dos anos 1990, com a nova reestruturação econômica mundial, a denominada globalização neoliberal, o sistema de educação superior catarinense também será modificado. Com a ideia de que a educação passa a ser também um produto de mercado, o sistema privado de natureza particular senso estrito, empresarial e com fins lucrativos, começa a competir com o modelo fundacional até então predominante. É uma nova fase da educação superior catarinense.

\section{A expansão das IES particulares}

O ano de 1997 marca o vertiginoso crescimento do número de IES em Santa Catarina, sobretudo de instituiçóes privadas com fins lucrativos. Como se pode observar no Gráfico 1, entre 1990 e 2015 o número de IES cresceu 370\% (de 20 em 1990, para 94, em 2015). A maior expansão se deu entre 2000 e 2005, um crescimento de 135,7\%, crescimento alavancado, sobretudo, pelas IES privadas com fins lucrativos, especialmente as que passaram a ofertar a modalidade a distância.

A expansão observada tem relação direta com a mudança do marco regulatório das políticas de educação superior introduzidas pela Lei de Diretrizes e Bases da Educação Nacional de 1996 (Lei no 9.394/96). A nova LDB desencadeou um processo de profunda reformulação do sistema de educação superior brasileiro.

Além da LDB, algumas outras leis sancionadas nos anos seguintes foram decisivas para reforçar a perspectiva privatizante do ensino superior. O legislativo brasileiro, por meio da Lei n. 9.870/99, ratificou a possibilidade de as IES operarem com fins lucrativos. O governo, por meio da Lei 


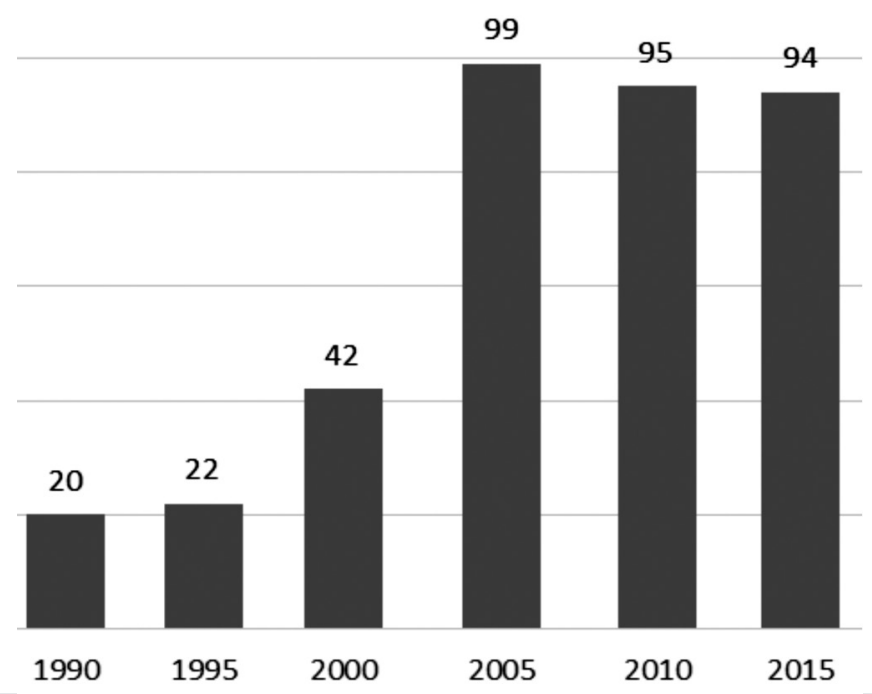

Gráfico 1: Evolução do número de IES em Santa Catarina (1990-2015) Fonte: INEP/MEC (2015). Elaboração dos autores.

n. 9.649/98, obstruiu o caminho da expansão da educação pública federal e impediu a União de expandir a oferta da educação profissional e tecnológica (RISTOFF; GIOLO, 2006). Por fim, o então Presidente da República vetou as metas do Plano Nacional de Educação, Lei n. 10.172/2001, itens 4.3,2 e 4.4,24, que previam a expansão da educação superior pública. Em virtude disso, as instituiçóes privadas tiveram um enorme crescimento, passando de 893, em 1990, para 2.416 IES, em 2012. O setor privado capitaneou a expansão: $87,5 \%$ das IES são privadas, respondendo por $73 \%$ das matrículas do país. (MEC/INEP, 2014)

Em Santa Catarina o setor privado (com e sem fins lucrativos) respondia, em 2015, por $88 \%$ das IES e cerca de $69 \%$ do total das matrículas.

Outra decorrência importante do marco regulatório que se esboça a partir da LDB é a expansão das faculdades. O crescimento se dá, portanto, na modalidade de IES que exige menor investimento em infraestrutura, qualificação docente e pesquisa.

As instituiçóes privadas com fins lucrativos ( for profit ${ }^{3}$ ) são, em geral, instituídas e mantidas por uma ou mais pessoas físicas ou jurídicas de direito privado que não apresentem as características de filantropia. Às 


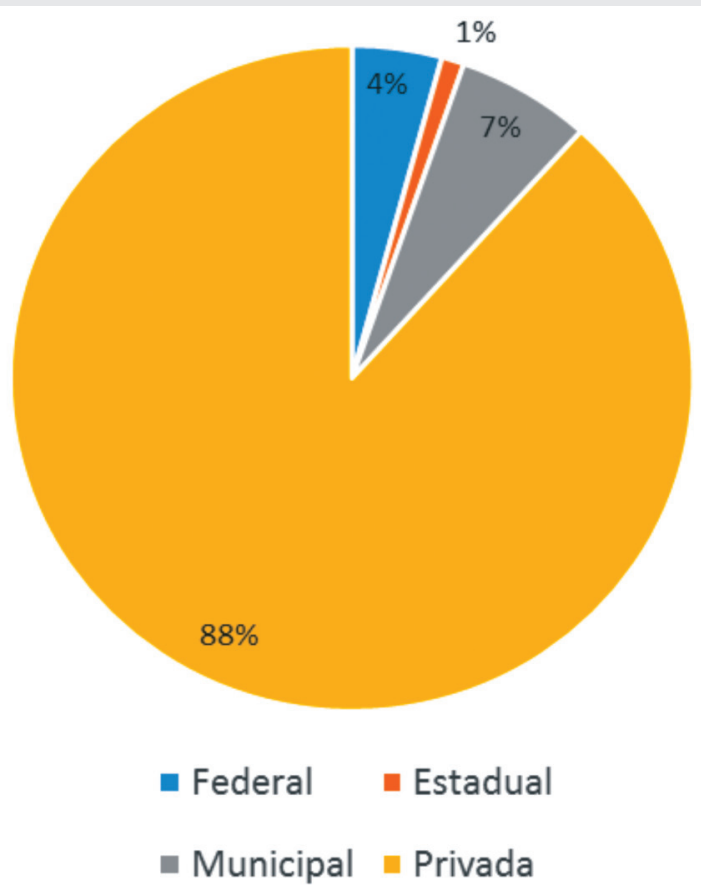

Gráfico 2: Distribuição das IES em Santa Catarina por dependência administrativa (2015)

Fonte: INEP/MEC (2015). Elaboração dos autores.

faculdades não é requisitada a oferta de cursos em diversas áreas de conhecimento, assim como não é exigida a pesquisa e a existência de programas de pós-graduaçáo stricto sensu. Como se pode observar no Gráfico 3, 73\% das IES catarinenses em 2015 definiam-se como faculdades.

\section{A interiorização das IES públicas}

Uma das características marcantes da educação superior catarinense, a exemplo do que ocorre em todo o território nacional, é a concentração da oferta de cursos no setor privado. Até 1989 a UFSC era a única IES a ofertar ensino público e gratuito no estado, ano em que a UDESC, atendendo ao estabelecido no Art. 169 da nova Constituição 


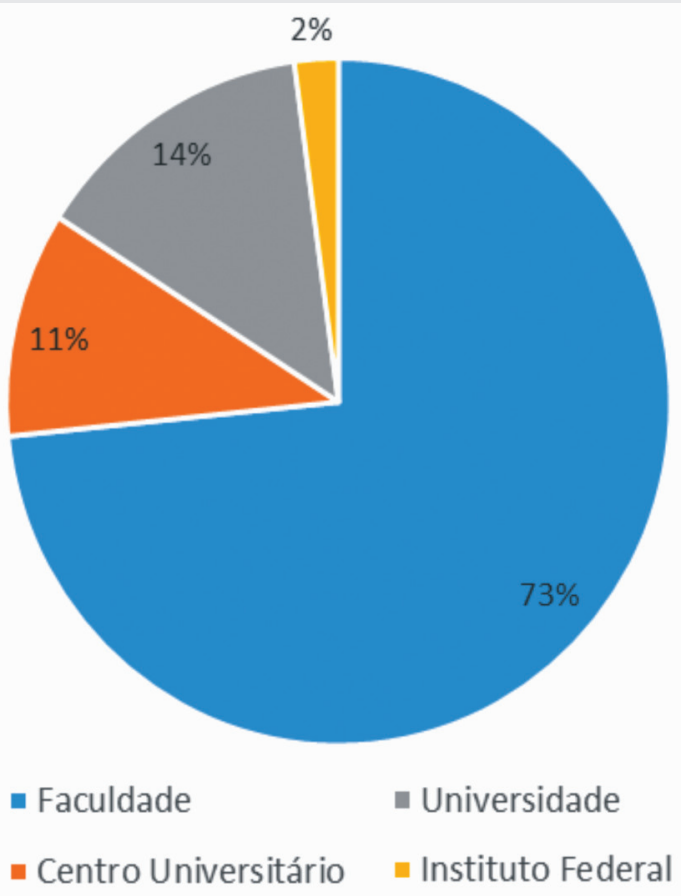

Gráfico 3: Distribuição das IES em Santa Catarina por organização acadêmica (2015)

Fonte: INEP/MEC (2015). Elaboração dos autores.

do Estado, interrompe a cobrança de mensalidades e passa a assegurar o princípio da gratuidade.

A expansão das IES públicas, especialmente para as cidades do interior, é muito recente. Nesse sentido, a UDESC ${ }^{4}$ (única universidade estadual) é pioneira por ter iniciado o movimento nessa direção em 2003, quando aprovou a implantação do Centro de Educação Superior do Oeste (Diário Oficial do Estado, no 17.086, de 31 de janeiro de 2003), autorizando a oferta dos cursos de Zootecnia (Chapecó), Enfermagem (Palmitos) e Engenharia de Alimentos (Pinhalzinho). A UFSC, por sua vez, manteve-se até 2009 como a única universidade federal sediada na capital do estado e estruturada em um único campus, ano em que aprovou a criação de seus três primeiros campi fora de Florianópolis nas cidades Araranguá, Joinville e Curitibanos. Em 2009 ocorreu também 
a criação da segunda universidade federal no estado, a Universidade Federal da Fronteira Sul (UFFS), com sede na cidade de Chapecó e $^{2}$ campi espalhados pelos 3 estados da região Sul. A interiorização foi impulsionada pelas políticas de expansão do governo federal, particularmente o Programa de Apoio a Planos de Reestruturação e Expansão das Universidades Federais (REUNI) ${ }^{6}$, o Programa Universidade Aberta do Brasil (UAB) e o Programa de Reestruturação da Rede Federal de Educação Profissional, Científica e Tecnológica.

A interiorização da educação superior também foi impulsionada pelo programa de expansão dos institutos federais. No bojo dessa política, o estado de Santa Catarina foi contemplado com dois institutos: o primeiro, com sede em Florianópolis (Instituto Federal de Educação, Ciência e Tecnologia de Santa Catarina - IFSC), e o segundo, em Blumenau (Instituto Federal de Educação, Ciência e Tecnologia Catarinense - IFC). Resultantes da aglutinação de escolas agrotécnicas e CEFETs já existentes, os institutos implantam campi $^{7}$ e cursos superiores em várias cidades do estado.

As instituiçóes públicas federais correspondem a $4 \%$ do total das IES catarinense. Do total de estudantes matriculados em cursos presenciais e a distância em SC, em 2015 (328.683 ao todo), as públicas respondiam por 79.724 matrículas. (MEC/INEP, 2017)

\section{A expansão da Educação a Distância}

A modalidade a distância vem, desde o início dos anos 2000, liderando o último e o mais recente ciclo de expansão da educação superior em SC. Como é possível observar no Gráfico 4, as matrículas em cursos de graduação (presencial e a distância) cresceram 419\% no período entre 1995 a 2015, passando de 64.201 para 333.308 matrículas (239.957 presenciais e 93.351 a distância).

Em 2015, a modalidade a distância já respondia por $28 \%$ do total de matrículas no estado. O ritmo anual de crescimento é bastante superior ao verificado na modalidade presencial. Enquanto o crescimento das matrículas presenciais no último decênio (2005-2015) foi de 23,5\%, passando de 194.130 para 239.957, o da educação a distância foi de 446\%, passando de 16.492 em 2005 para 93.351 em 2015. 
239.957

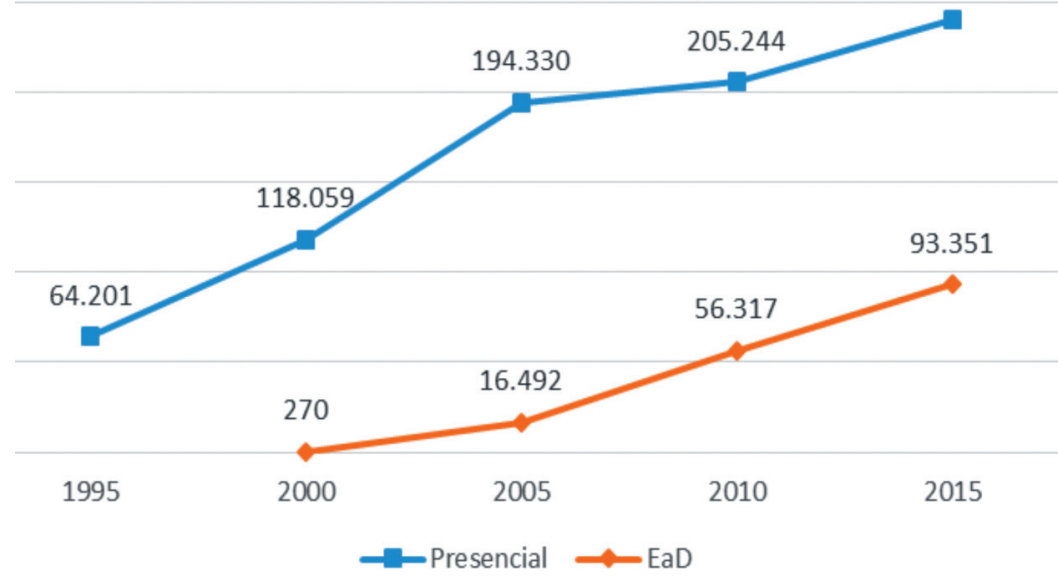

Gráfico 4: Distribuição das matrículas em cursos de graduação presencial e a distância em Santa Catarina (1995-2015)

Fonte: INEP/MEC (1995-2015). Elaboração dos autores.

\section{Consideraçóes finais}

Ao celebrarmos o $1^{\circ}$ centenário da educação superior catarinense, é necessário afirmar que se trata de um período, embora iniciado tardiamente, com destacadas conquistas e, por vezes, contradiçóes. Os diferentes períodos de evolução da educação superior catarinense revelam que os avanços, numa perspectiva de desenvolvimento social, eram mais contundentes em alguns tempos e espaços, enquanto em outros apenas atendiam a grupos estratificados da sociedade. Essa evolução decorre dos desafios políticos, econômicos, sociais e culturais que se apresentaram nos diferentes tempos e espaços.

$\mathrm{Na}$ gênese do sistema de educação superior catarinense, o que era próprio do tempo e do espaço, o acesso à educação superior por meio de faculdades isoladas criadas pelo Instituto Politécnico era restrito a grupos muito seletos de pessoas situadas, principalmente, na capital. A criação da primeira universidade pública gratuita foi, com certeza, um marco importante, pois colocou o estado numa outra perspectiva de desenvolvimento, 
agora não mais só com o ensino, mas também com a pesquisa e a extensão. Embora tenha ampliado o acesso à educação superior, a educação superior ainda continuava mais vinculada ao litoral catarinense.

Os anos de 1960 são marcantes do ponto de vista da expansão da educação superior para outras regióes do estado. Nesse período começa uma relação de pertinência entre governos e sociedade civil. Por mais de 2 décadas, por incapacidade financeira para ampliar o sistema público gratuito e por direcionamento político, o estado incentivou a criação de fundações educacionais isoladas que irão articular a expansão da educação superior para todas as regióes. É a primeira fase da expansão do acesso a cursos superiores. É nessa primeira fase da expansão que foi criada a UDESC, seguindo os mesmos moldes das demais fundações cuja viabilização econômica estava lastreada na cobrança de mensalidades. Em 1989, quando da reestruturação da Constituição Estadual, a UDESC só se tornou totalmente pública e gratuita por causa dos movimentos da sociedade civil, especialmente os de estudantes e professores. A UDESC também desempenhou um papel importante na expansão da educação superior no Estado.

$\mathrm{O}$ segundo período da expansão foi marcado pela transformação das faculdades isoladas em universidades. Algumas instituiçôes conseguem com mais facilidade essa ascensão; entretanto, outras precisam se juntar para alcançar esse objetivo. O que vemos também é uma política de conveniência, pois as rivalidades regionais que eram muito presentes e causavam divisóes agora se enfraquecem, dando espaço à adesão.

De certa forma, é possível considerar que, embora existisse o incentivo do Estado para a expansão da educaçáo superior para outras regiōes, a responsabilidade de manutenção financeira ficava sob a responsabilidade dos municípios, entes criadores das fundações, num primeiro momento, e, na sequência, da própria instituição que era obrigada a cobrar mensalidades para a sua manutenção. Há aqui uma política de conivência do estado ou até mesmo do país com relação ao oferecimento da educação superior.

A segunda metade da década de 1990 é marcada pela ampliação do sistema privado particular. Muitas instituiçóes privadas, até então presentes na capital e nos grandes centros do País, migram para as diferentes regióes do estado, desestabilizando, de certa forma, o sistema existente. A concorrência aumenta e a política de diplomação sem compromisso social com o processo de aprendizagem e a pesquisa se torna mais evidente. 
$\mathrm{Na}$ contrapartida do sistema privado particular, mercantil, outra luz se acende: a ampliação do sistema público gratuito, com três novos campi da UFSC, extensóes da UDESC e o campus da UFFS, além dos institutos federais em grande parte dos municípios do estado. Esse fenômeno com certeza produziu novas expectativas de desenvolvimento para toda Santa Catarina.

$\mathrm{Na}$ atualidade, embora ainda com uma participação muito pequena do setor público gratuito e mesmo considerando suas dimensôes e realidades espaciais socioeconômicas contraditórias, Santa Catarina é o terceiro estado em desenvolvimento humano no país. E para isso pode contar, certamente, com a participação dos profissionais formados pelas instituiçóes de educação superior ao longo desses 100 anos.

\section{Notas}

1 O I PLAMEG, fez parte da administração do Governador Celso Ramos (gestão de 31/01/1961 a 31/01/1966).

2 Modelo semelhante ou inspirado ao que aconteceu com a criação das universidades federais brasileiras nas décadas de 1940 a 1960.

3 Termo utilizado pela professora Helena Sampaio (2000).

4 A UDESC tivera a experiência de implantação do curso de Veterinária na cidade de Lages, 1973, o que pode ser considerado sua primeira investida no interior. Contudo esta investida náo apresentou o mesmo potencial de expansão como a implantação, em 2003, do campi no Oeste, no que se refere à acesso e oferta de cursos e vagas.

5 Criada em 2009 por meio da Lei no 12.029/09, a UFFS implantou os seus primeiros cursos de graduação em março de 2010, tendo hoje, no campus de Chapecó, 13 cursos de graduação, 4 mestrados e 1 doutorado na modalidade DINTER, além de outros cursos de especialização já concluídos e alguns, em funcionamento.

6 As políticas de expansão do governo federal resultaram na criaçấo de 24 novas universidades federais entre os anos 2000 e 2014, além de centenas de novos campi, passando de 148 em 2002, para 321, em 2014 (MEC/INEP, 2014).

7 O IFC foi criado pela Lei Federal no 11.892/2008, com a integração das escolas agrotécnicas de Concórdia, Rio do Sul e Sombrio e dos colégios agrícolas de Araquari e Camboriú, que eram vinculados à Universidade Federal de Santa Catarina. O IFC possui, atualmente, 15 campi em Santa Catarina. O IFSC, por sua vez, possui 22 campi em Santa Catarina.

\section{Referências}

BRASIL. Lei no 10.172, de 9 de janeiro de 2001. Aprova o Plano Nacional de Educação e dá outras providências. Diário Oficial da União, Brasília, DF, 10 jan. 2001, p. 1. Disponível em: <http://www.planalto.gov.br/ccivil_03/leis/leis_2001/110172. htm>. Acesso em: 23 fev. 2016. 
Lei no 4.024, de 20 de dezembro de 1961. Fica as Diretrizes e Bases da Educação Nacional. Diário Oficial da União, Brasília, DF, 27 dez. 1961. Disponível em: http://www.planalto.gov.br/ccivil_03/LEIS/L4024.htm. Acesso em: 11 dez. 2018.

. Lei no 5.540, de 28 de novembro de 1968. Fixa normas de organização e funcionamento do ensino superior e sua articulação com a escola média, e dá outras providências. Diário Oficial da União, Brasília, DF, 23 nov. 1968. Disponível em: < http://www.planalto.gov.br/ccivil_03/LEIS/L5540.htm>. Acesso em: 11 dez. 2018

. Lei no 7.596, de 10 de abril de 1987. Altera dispositivos do Decreto-lei no 200 , de 25 de fevereiro de 1967, modificado pelo Decreto-lei no 900, de 29 de setembro de 1969, e pelo Decreto-lei no 2.299, de 21 de novembro de 1986, e dá outras providências. Diário Oficial da União, Brasília, DF, 11 abr. 1987. Disponível em: < http://www.planalto.gov.br/ccivil_03/LEIS/L7596.htm>. Acesso em: $11 \mathrm{dez} .2018$.

CUNHA, Luiz Antônio. A universidade temporã: o ensino superior, da Colônia à Era Vargas. 3. ed. rev. São Paulo: Editora UNESP, 2007.

FRANTZ, Walter. Universidade comunitária: uma iniciativa pública não-estatal em construção. Cadernos Inijuí. Ijuí, RS: Editora Unijuí, 2004.

FREITAG, Barbara. Escola, estado e sociedade. São Paulo: Moraes, 1980.

GUMBOWSKY, Argos. O ensino superior nas universidades fundacionais municipais catarinenses: a gênese de um modelo de ensino superior comprometido com o desenvolvimento regional. In: CONGRESSO BRASILEIRO DE HISTÓRIA DA EDUCAÇÃO, 3., 2004, Curitiba. Anais eletrônicos... Curitiba: PUCPR, 2004.

Disponível em: <http://www.sbhe.org.br/novo/congressos/cbhe3/Documentos/Individ/ Eixo3/460.pdf>. Acesso em: 30 jun. 2016.

MEC/INEP. Censo da Educação Superior 2014. Disponível em: <http://portal.inep.gov. br/web/censo-da-educacao-superior>. Acesso em: 01 jul. 2015.

MEC/INEP. Censo da Educação Superior 2015. Disponível em: <http://portal.inep.gov. br/web/censo-da-educacao-superior>. Acesso em: 18 ago. 2016.

MEC/INEP. Censo da Educação Superior 2017. Disponível em: <http://portal.inep.gov. br/web/censo-da-educacao-superior>. Acesso em: 24 set. 2018.

MUNIZ, M. D. Educação superior em Santa Catarina: consolidação e expansão. 2006, 261 f. Tese (Doutorado Engenharia de Produção) - Universidade Federal de Santa Catarina, Florianópolis.

PEGORARO, Ludimar. O terceiro setor e o ensino superior no Brasil: o sistema fundacional catarinense. In.: PERONI, Vera Maria Vidal; BAZZO, Lúcia; PEGORARO, Ludimar; COSTA, Áurea de Carvalho [et al.] (Org.). Dilemas da educação brasileira em tempos de globalização neoliberal: entre o público e o privado. Porto Alegre: Editora da UFRGS, 2006. . Terceiro setor na educação superior brasileira. Campinas: Leitura Crítica, 2013. 
RISTOFF, Dilvo; GIOLO, Jaime. A educação superior no Brasil - Panorama Geral. In: BRASIL. Ministério da Educação/INEP/DEAES. Educação Superior Brasileira 1991-2004. Santa Catarina. Brasília: INEP, 2006.

ROMANELLI, Otaíza de Oliveira. História da educação no Brasil. 11a ed. Petrópolis: Vozes, 1989.

SAMPAIO, H. O ensino superior no Brasil: o setor privado. São Paulo: Hucitec, 2000.

SAVIANI, Dermeval. História das ideias pedagógicas no Brasil. São Paulo: Autores Associados, 2007.

SAVIANI, Dermeval. A expansão do ensino superior no Brasil: mudanças e continuidades. Poíesis Pedagógica. vol. 8, n. 2, Ago./Dez. 2010.

TREVISOL, Joviles. A pós-graduação na Universidade Federal da Fronteira Sul: interiorização e redução de assimetrias em região de fronteira. $R B P G$, Brasília, v. 12 , n. 28, p. 505-532. Ago. 2015.

UNIVERSIDADE PARA O DESENVOLVIMENTO DO ESTADO DE SANTA CATARINA (UDESC). Estudo da viabilidade técnica e financeira para instalação de curso de nivel superior em Joaçaba: FUOC - Fundação Universitária do Oeste Catarinense. Joaçaba: Prefeitura Municipal de Joaçaba; Universidade para o Desenvolvimento do Estado de Santa Catarina, nov. 1969. (Elaboração: Reitoria da UDESC).

Recebido em 7 out. 2017 / Aprovado em I6 out. 2018

\section{Para referenciar este texto:}

BASTIANI, S. C.; TREVISOL, J. V.; PEGORARO, L. A educação superior em Santa Catarina: um século de história (1917-2017). EccoS - Revista Científica, São Paulo, n. 47, p. 375-395. set/dez. 2018. Disponível em: <https://doi.org/10.5585/ EccoS.n47.7974>. 
